Article

\title{
Investigation of High-Energy Ion-Irradiated MA957 Using Synchrotron Radiation under In-Situ Tension
}

\author{
Kun Mo ${ }^{1, *}$, Di Yun ${ }^{1,2}$, Yinbin Miao ${ }^{1}$, Xiang Liu ${ }^{3}$, Michael Pellin ${ }^{1}$, Jonathan Almer ${ }^{4}$, \\ Jun-Sang Park ${ }^{4}$, James F. Stubbins ${ }^{3,5}$, Shaofei Zhu ${ }^{6}$ and Abdellatif M. Yacout ${ }^{1}$ \\ Received: 31 October 2015; Accepted: 24 December 2015; Published: 2 January 2016 \\ Academic Editor: Jie Lian \\ 1 Nuclear Engineering Division, Argonne National Laboratory, Lemont, IL 60439, USA; \\ diyun1979@mail.xjtu.edu.cn (D.Y.); ymiao@anl.gov (Y.M.); pellin@anl.gov (M.P.); yacout@anl.gov (A.M.Y.) \\ 2 Department of Nuclear Engineering, Xi'an Jiaotong University, Xi'an 710049, Shaanxi, China \\ 3 Department of Nuclear, Plasma, and Radiological Engineering, University of Illinois at Urbana-Champaign, \\ Urbana, IL 61801, USA; xliu128@illinois.edu (X.L.); jstubbin@illinois.edu (J.F.S.) \\ 4 Advanced Photon Source, Argonne National Laboratory, Lemont, IL 60439, USA; almer@aps.anl.gov (J.A.); \\ parkjs@aps.anl.gov (J.-S.P.) \\ 5 International Institute for Carbon-Neutral Energy Research (I2CNER), Kyushu University, \\ Fukuoka 819-0395, Japan \\ 6 Physics Division, Argonne National Laboratory, Lemont, IL 60439, USA; zhu@anl.gov \\ * Correspondence: kunmo@anl.gov; Tel.: +1-630-252-7417
}

\begin{abstract}
In this study, an MA957 oxide dispersion-strengthened (ODS) alloy was irradiated with high-energy ions in the Argonne Tandem Linac Accelerator System. Fe ions at an energy of $84 \mathrm{MeV}$ bombarded MA957 tensile specimens, creating a damage region $~ 7.5 \mu \mathrm{m}$ in depth; the peak damage ( $\sim 40 \mathrm{dpa}$ ) was estimated to be at $\sim 7 \mu \mathrm{m}$ from the surface. Following the irradiation, in-situ high-energy X-ray diffraction measurements were performed at the Advanced Photon Source in order to study the dynamic deformation behavior of the specimens after ion irradiation damage. In-situ X-ray measurements taken during tensile testing of the ion-irradiated MA957 revealed a difference in loading behavior between the irradiated and un-irradiated regions of the specimen. At equivalent applied stresses, lower lattice strains were found in the radiation-damaged region than those in the un-irradiated region. This might be associated with a higher level of Type II stresses as a result of radiation hardening. The study has demonstrated the feasibility of combining high-energy ion radiation and high-energy synchrotron $X$-ray diffraction to study materials' radiation damage in a dynamic manner.
\end{abstract}

Keywords: synchrotron radiation; oxide dispersion-strengthened (ODS); ion irradiation; in situ tensile test

\section{Introduction}

MA957 is a ferritic oxide dispersion-strengthened (ODS) alloy originally developed by INCO at the end of the 1970's [1,2]. As with many ODS materials, MA957 has exceptional high-temperature strength, creep resistance, and oxidation resistance [3]. The mechanical superiority of MA957 over traditional ferritic materials stems from its unique nano-feature: a high density of nano-scale particles or nano-clusters embedded in the metallic matrix. Under irradiation, these nano-scale particles serve as traps of He and point defects, and thus significantly improve the materials' swelling resistance [4]. MA957 is considered one of most promising structural materials for advanced reactor systems (e.g., fast reactors and fusion systems) due to its outstanding radiation resistance [5]. To better understand the properties of MA957 and further improve its mechanical performance and radiation resistance, 
decades have been spent performing numerous studies. The mechanical properties including tensile properties, fracture toughness, and creep resistance have been studied at various temperatures and under various test conditions [5-8]. Multiple advanced materials characterization techniques, including atom probe tomography (APT), small angle neutron scattering (SANS), and high-resolution transmission electron microscopy (HRTEM), have been employed to systematically investigate the stoichiometry, crystal structure, size, density, and stability of nano-particles/nano clusters within MA957 [9-14]. Microstructural development of MA957 after neutron radiation, an important reference for possible nuclear applications of the alloy, has been extensively studied at different temperature and doses [1,15-20].

Development of radiation resistant materials requires long-term and systematic in-reactor tests to evaluate irradiation damage as a function of temperature and dose. However, the high cost and long irradiation required for in-reactor testing hinders the progress of nuclear materials development. Recent advances in studying heavy ion irradiations have shown great potential for emulating reactor irradiation damage using ion beams [21,22]. One of the main disadvantages of using heavy ion irradiation is the limited depth of penetration with the ion beam [23]. To considerably extend the depth of ion penetration and thereby attain a larger radiation-damaged region, we employed a $84 \mathrm{MeV} F$ ion beam, of an energy much higher than those available from lab-based accelerators. The irradiated specimen was then tensile tested with an in-situ synchrotron diffraction measurement. The dynamic responses of un-irradiated and irradiated regions within one single specimen were obtained. This set of experiments demonstrated the feasibility of combining high-energy ion radiation and high-energy synchrotron X-ray diffraction to study materials' radiation damage in a dynamic manner.

\section{Materials and Experimental Procedure}

The nominal composition of MA957 is $14 \mathrm{Cr}-1 \mathrm{Ti}-0.3 \mathrm{Mo}-0.25 \mathrm{Y}_{2} \mathrm{O}_{3}$ (wt \%). The material contains $\sim 5 \mathrm{~nm}$ nanoclusters [24] in grains approximately $500 \mathrm{~nm}$ in size. Figure 1 shows the typical microstructure of MA957. The material was machined into SS-J1 type miniature tensile specimens with a gauge section of $1.2 \mathrm{~mm} \times 0.25 \mathrm{~mm} \times 5 \mathrm{~mm}$ (width $\times$ thickness $\times$ length). The tensile specimens were polished first with 600 grit $\mathrm{SiC}$ abrasive paper, then by $3 \mu \mathrm{m}$ alumina suspensions, and finished with $0.02 \mu \mathrm{m}$ colloidal silica. The high-energy $(84 \mathrm{MeV}) \mathrm{Fe}$ ion irradiation of the specimens was performed in the Argonne Tandem Linac Accelerator System (ATLAS) at Argonne National Laboratory (ANL). The Fe ion beam with a charge state of +11 was tuned to a Gaussian shape with a full width half maximum (FWHM) of $5.2 \mathrm{~mm}$. The exposure area was controlled to be $\sim 10 \mathrm{~mm}$ in diameter by setting up a collimator in front of the sample stage. Two specimens were loaded on the sample stage and irradiated simultaneously (Figure 2a). The large beam size allowed high-energy ion exposure of the entire gauge and part of the grip section of the miniature tensile specimens (Figure $2 b$ ). Each of the tensile specimens was placed $1.7 \mathrm{~mm}$ from the ion beam center in order to achieve relatively uniform radiation damage in the gauge part of the sample. The gauge region (shown as the pale blue rectangular region in Figure $2 \mathrm{~b}$ ) of each sample absorbed $\sim 9.4 \%$ of the total beam current. The average dose rate was $\sim 8 \times 10^{11}$ ions $/\left(\mathrm{cm}^{2} \cdot \mathrm{s}\right)$, and the achieved dose in the gauge region was $\sim 4.4 \times 10^{16}$ ions $/ \mathrm{cm}^{2}$. A thermocouple was attached to the back side of each tensile specimen in order to provide continuous temperature measurement during the experiment. The stabilized sample temperature during the experiment was measured to be $\sim 250^{\circ} \mathrm{C}$.

Based on the average dose achieved in the gauge portion of the tensile specimens, the implanted Fe ion concentrations (in ppm) and radiation damage (in displacements per atom, dpa) were calculated by the SRIM (stopping and range of ions in matter) computer code [25,26]. A value of $40 \mathrm{eV}$ displacement threshold energy and the Kinchin-Pease option were used in the SRIM calculation following the recommendations in reference [27]. The ion irradiation produced a damaged region of $\sim 7.5 \mu \mathrm{m}$ in depth, while the peak damage ( $40 \mathrm{dpa}$ ) was estimated to be $\sim 7 \mu \mathrm{m}$ from the surface (Figure 3). The average damage levels from the surface to the depth of $\sim 7.5 \mu \mathrm{m}$ (over the damaged region) and $10 \mu \mathrm{m}$ (over a single X-ray scan step) were $\sim 7.4$ and $\sim 5.7 \mathrm{dpa}$, respectively. 


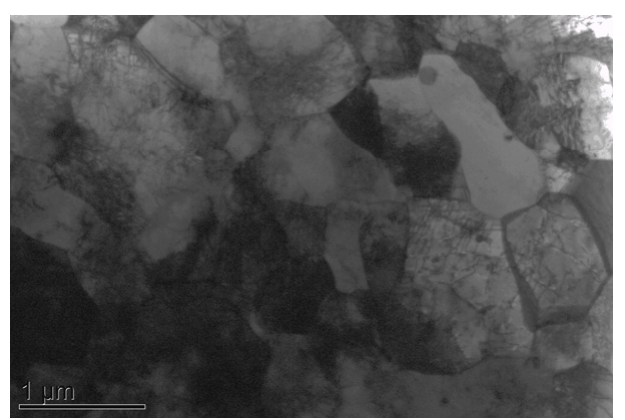

Figure 1. Transmission electron microscopy (TEM) image of the MA957 sample before ion-irradiations.

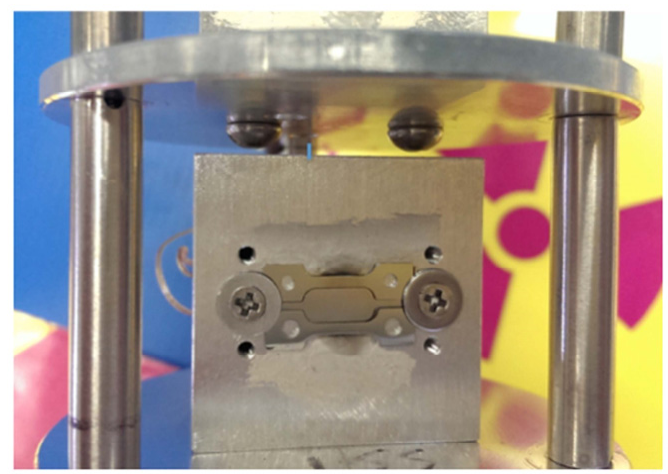

(a)

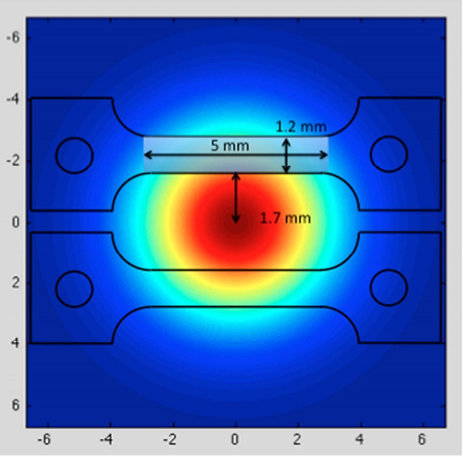

(b)

Figure 2. (a) Experimental set-up for irradiating tensile specimens at Argonne Tandem Linac Accelerator System (ATLAS); (b) Schematic of the Gaussian beam exposure profile of tensile specimens (axes units: $\mathrm{mm}$ ).

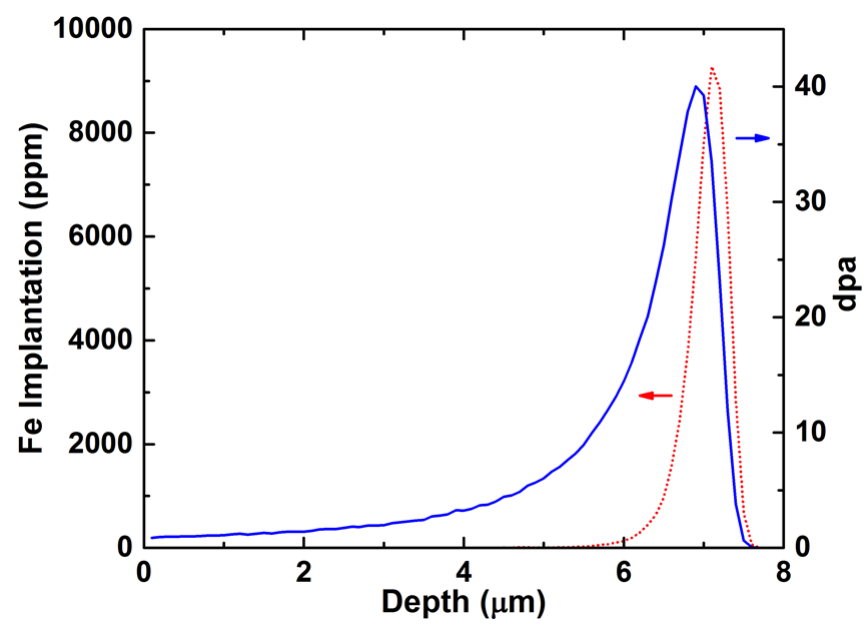

Figure 3. Implanted Fe ion concentration (in ppm) and radiation damage (in dpa) of the irradiated MA957 tensile sample.

The in-situ high-energy X-ray diffraction experiment was conducted at the 1-ID beamline of the Advanced Photon Source (APS), ANL. One of the irradiated specimens and one un-irradiated MA957 tensile specimen (as a control sample) were deformed in uniaxial tension using an MTS closed-loop servo-hydraulic test frame (model 858) at room temperature. To perform the X-ray diffraction measurements during tensile testing, the specimen was installed on the grips without any 
applied load from the MTS test frame. After specimen placement, a $0.1 \mathrm{~N}$ load (stress of $\sim 88 \mathrm{MPa}$ ) was applied to fix the specimen in position. During tensile testing, the gauge part of the specimen was exposed to the high-energy monochromatic X-ray beam $(86 \mathrm{keV})$, and the diffraction patterns were collected by an amorphous Si detector from General Electric (GE) with a pixel size of $200 \mu \mathrm{m}$. Two different types of in-situ measurements were performed on the two tensile specimens: (1) a continuous (non-stop) tensile test with X-ray diffraction to measure the bulk response of the un-irradiated MA957 and (2) an intermittent tensile test with X-ray diffraction scanning across the cross-section in order to capture the response in the radiation-damaged region near the sample surface of the ion-irradiated MA957. Figure 4 shows the experimental setup and the sample orientation during the in-situ tensile tests. A schematic of the X-ray diffraction measurement of the un-irradiated and ion-irradiated samples is shown in Figure 5. The bulk measurement of the un-irradiated specimen was done using a typical continuous in-situ tensile test with X-ray diffraction characterization. The strain rate was approximately $2 \times 10^{-4} \mathrm{~s}^{-1}$ based on the displacement rate of the load frame crosshead and the length of the gauge section. The size of X-ray beam was $100 \times 100 \mu \mathrm{m}^{2}$. The distance between the sample and the detector was $\sim 1.4 \mathrm{~m}$. Similar experimental setup and procedures can be found in references [28-33]. A unique X-ray diffraction scanning routine was designed specifically to characterize the ion-irradiated specimen. After loading the specimen on the MTS machine, the surface of irradiated specimen was oriented to be parallel to X-ray beam, i.e., $90^{\circ}$ off from the orientation of the un-irradiated specimen during its continuous tensile test. To accurately align the sample, its orientation was adjusted by using the rotation stage under the MTS machine at each stress-strain state during tensile testing. This orientation adjustment relied on the measurement of attenuated X-rays when scanning the cross-section of the sample. The beam size was reduced to $10 \times 10 \mu \mathrm{m}^{2}$ using defining slits. The beam energy was set to $\sim 65 \mathrm{keV}$ to attain a better resolution, while the distance between the sample and the detector was maintained to be $\sim 1.4 \mathrm{~m}$. During the early stage of the tensile test (before sample yielding), load control mode was used to strain the sample to a preset load, then the sample was held at that load to allow X-ray diffraction scanning. The X-ray diffraction scanned from the sample surface (Figure 5b) to $\sim 75 \mu \mathrm{m}$ depth with a step size of $10 \mu \mathrm{m}$. The first step measurement was used to represent the irradiated region. Once sample yielding was observed, the load control mode was changed to strain control mode to avoid overloading the tensile specimen. This intermittent tensile test has been shown to yield similar material performance to the continuous tensile test at low temperatures, and has been applied to study materials' behavior with in-situ wide-angle X-ray and neutron scattering [32,34-40].

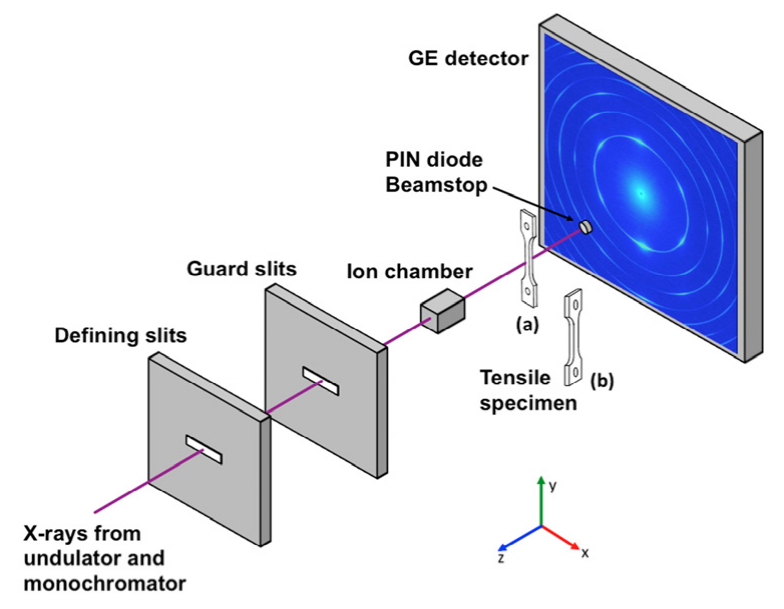

Figure 4. Schematic of the synchrotron experimental setup; the diffraction pattern in the schematic is from the bulk measurement of the un-irradiated MA957 tensile specimen. Sample position (a) is for bulk measurement of the un-irradiated MA957 tensile specimen; and sample position (b) is for X-ray diffraction scan of the ion-irradiated MA957 tensile specimen. 


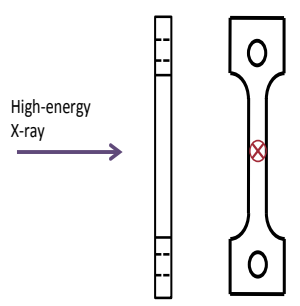

(a)
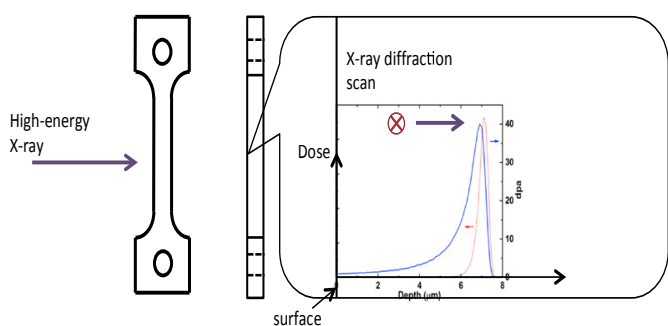

(b)

Figure 5. Schematic of the X-ray diffraction measurement of: (a) un-irradiated MA957, i.e., the bulk measurement; and (b) ion-irradiated MA957 by in-depth cross-section scanning. The red circles with cross show the $\mathrm{X}$-ray inlet direction.

\section{Results}

Figure 6 shows the stress-strain diagram of the MA957 alloy. The engineering stress, $\sigma_{e}$, was calculated by $\sigma_{\mathrm{e}}=F / A$, where $F$ is the load on the sample and $A$ is the area of the cross-section. $F$ was measured by the MTS loading frame, while $A$ was measured before the tensile test. The entire stress-strain curve was only achieved by tensile testing the un-irradiated bulk MA957 sample. The $0.2 \%$ yield strength (YS) was measured to be $\sim 810 \mathrm{MPa}$. The ultimate tensile strength (UTS) was measured to be $\sim 918 \mathrm{MPa}$, developed at a strain of $\sim 13.4 \%$. Sample necking began after the sample reached the UTS and continued until sample failure. The total elongation of the $9 \mathrm{Cr}$ ODS sample was $\sim 24.1 \%$. For the tensile test of the irradiated specimen, only six individual measurements along the stress-strain curve were conducted because the sample failed when loading to the seventh position in plastic deformation. However, all the measured points fell along the stress-strain curve developed by the continuous test, and this directly confirmed the material's similar mechanical response for intermittent and continuous tensile tests.

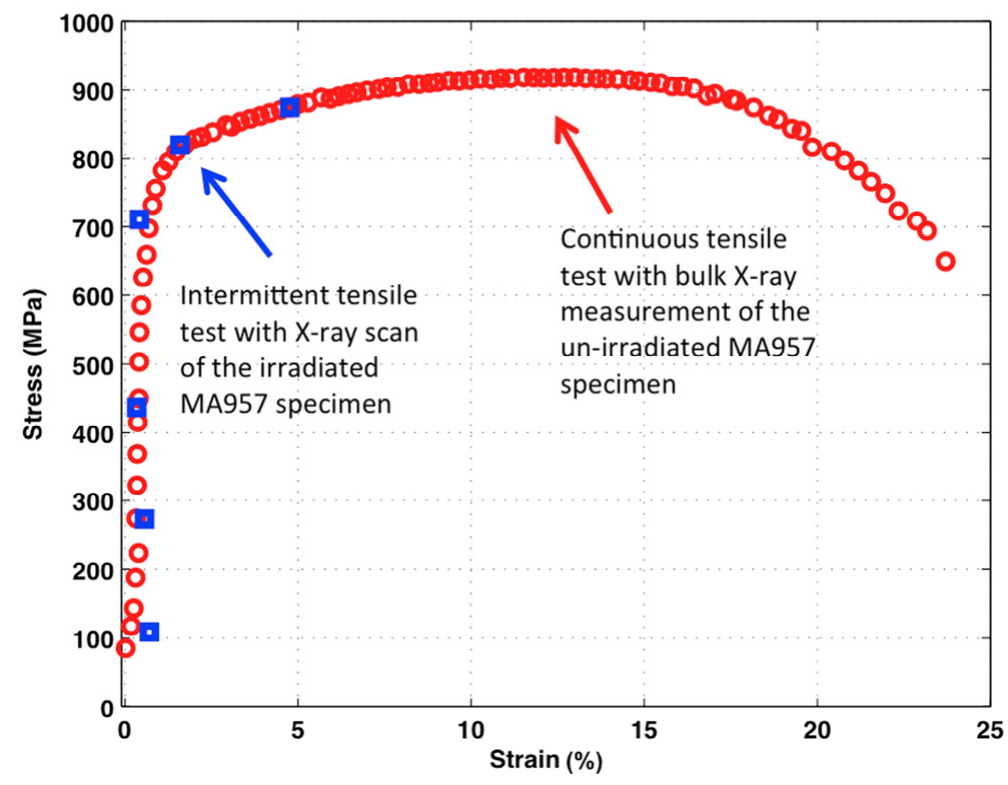

Figure 6. Engineering stress-strain diagram of MA957: the blue squares show stress and strain values during the intermittent tensile test for the irradiated MA957 specimen; the red circles show stress and strain values during the continuous tensile test for the un-irradiated MA957 specimen.

Figure 7 shows the diffraction pattern of the un-irradiated MA957. A strong $\{110\}$ texture was observed. The lattice constant of MA957 was measured to be $2.873 \AA$. Since a small beam size was 
used, a limited X-ray diffraction volume was obtained when measuring the ion-irradiated specimen. Moreover, due to the developed texture in the MA957 sample, only the $\{110\}$ reflection of the $\alpha$-Fe matrix provided sufficient statistics in the tensile direction (i.e., $90^{\circ}$ in Figure 7 ) when measuring the irradiated sample. To study and compare the dynamic response of both materials during tensile testing, the strain in the $\{110\}$ family of planes in the $\alpha$-Fe matrix was calculated based on the equation [32,41-45]:

$$
\varepsilon_{\text {lattice }}=\frac{d_{\sigma}-d_{0}}{d_{0}}
$$

where $d_{\sigma}$ is the $d$-spacing of a $\{110\}$ reflection measured at a specific stress $\sigma$ and at the $90^{\circ}$ (i.e., tensile direction) of the $\{110\}$ Debye ring. The $d_{0}$ is the reference $d$-spacing measured before loading the specimen. Figure 8 shows the results of the lattice strain evolution for both the un-irradiated and irradiated MA957 samples. As the testing was done continuously, the lattice strain of un-irradiated MA957 evolves smoothly. With applied load, the lattice strain linearly increases in the elastic regime until yielding (red circles in Figure 8). Similar to many materials with multiple phases [18-20,26], in the transition process from elastic to plastic deformation, the lattice strain of the metallic matrix decreases during early yielding but increases afterwards until necking. Compared to the homogeneous microstructure within the un-irradiated sample, the ion-irradiated MA957 has two regions that need to be separately characterized. By using X-ray diffraction scanning with small beam size, both the radiation-damaged region near the sample surface and the un-irradiated region at the inner part of the sample were measured; their lattice strains were calculated and are shown in Figure 8. The lattice strain development in the un-irradiated regions is consistent with the bulk measurement of the un-irradiated specimens, although the deviation from the elastic linearity was not caught due to the small number of measurements during sample yielding. During the early stage of elastic deformation, the loading behavior of the radiation-damaged and the un-irradiated regions in the irradiated sample are also consistent with the bulk measurement of the un-irradiated specimens. The divergence of the lattice strain development in the radiation-damaged region starts at a stress of $700 \mathrm{MPa}$, about $100 \mathrm{MPa}$ below the yield strength. Upon plastic deformation, the difference between the lattice strain developed in the irradiated and un-irradiated regions increases significantly; its value jumped from $\sim 0$ at $430 \mathrm{MPa}$ to $4 \times 10^{-4}$ at $815 \mathrm{MPa}$. This indicates that the internal stress of the metallic matrix in the radiation-damaged region is much smaller than that in the un-irradiated region of the same specimen.

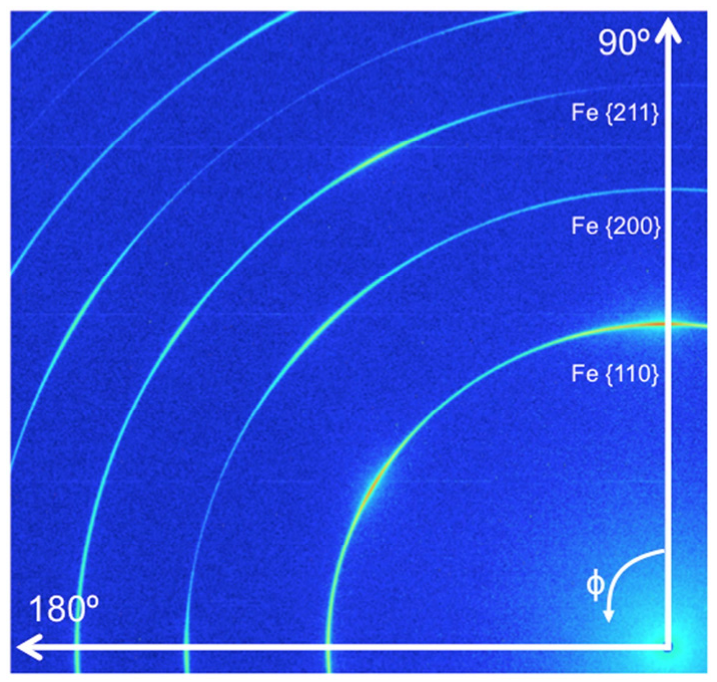

Figure 7. Diffraction pattern of un-irradiated MA957; the tensile direction is at $90^{\circ}$. 


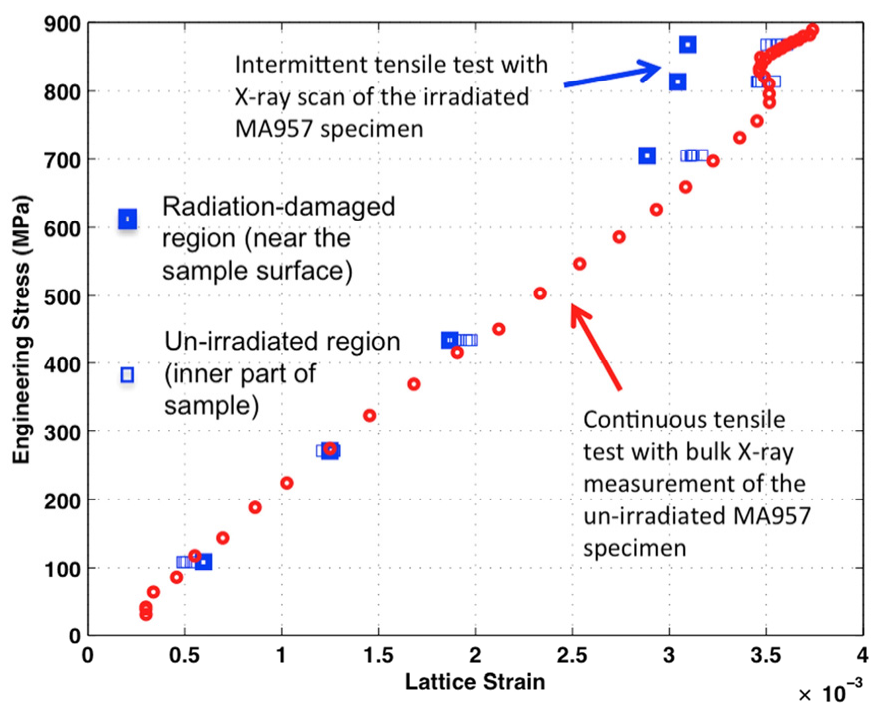

Figure 8. $\{110\}$ lattice strain evolutions for both un-irradiated and irradiated MA957 samples: the blue squares show lattice strain values during the intermittent tensile test for the irradiated MA957 specimen; the red circles show lattice strain values during the continuous tensile test for the un-irradiated MA957 specimen. The uncertainty in lattice strains is about $\pm 4 \times 10^{-4}$.

\section{Discussion}

The surface condition is critical for ion-irradiation study, especially when using a lab-based accelerator wherein the induced irradiation damage is concentrated in the near-surface region. The high-energy ions used in the present study produced a $\sim 7.5 \mu \mathrm{m}$ deep damage region. Thus there is much less sensitivity to the surface condition than when irradiating with lower energy ions. However, electropolishing should be applied to the specimens in further irradiation experiments to provide a smooth and hardening-free sample surface.

As shown in Figure 6, bulk stress-strain responses of the irradiated and un-irradiated regions are consistent, indicating that the impact of the high-energy ion irradiation on the overall tensile sample is negligible. Even though the Fe ion energy is much higher than regular lab-based accelerators, the radiation-damaged region is limited to $<10 \mu \mathrm{m}$ from the surface. Similar lattice strain developments in the un-irradiated sample and the un-irradiated region of the irradiated sample also suggest that the high-energy radiation damage is localized in the near-surface region. This provides us an opportunity to investigate the dynamic responses of un-irradiated and irradiated materials by applying a high-energy $\mathrm{X}$-ray scan to both un-irradiated and irradiated regions within a single specimen. Note that the un-irradiated region in the irradiated sample experienced similar temperature exposure during the high-energy ion irradiation; the temperature gradient along the range of $\mathrm{X}$-ray diffraction scan (surface to the $75 \mu \mathrm{m}$ depth) was insignificant based on the heat transfer calculation. Thus, the comparison between these two regions within a sample is even better than the comparison to the un-irradiated/control sample.

The radiation effect on the tensile specimen was not evident during the early stage of elastic deformation, indicating that the elastic constant of the MA957 was not changed after high-energy ion irradiation. The difference in lattice strain between the radiation-damaged region and the un-irradiated region became significant when the specimen was loaded near the YS, where the lattice strains began to deviate from the elastic linearity. This phenomenon of deviation from elastic linearity during yielding (Figure 8) is often attributed to the development of Type II stresses [46]. Type II stresses universally exist in polycrystalline metals, and are more significant in multi-phase materials because of the larger discrepancy between phases $[47,48]$. Compared to the un-irradiated region, the ion-irradiated MA957 region developed higher levels of Type II stresses that resulted in a more significant deviation from the 
elastic linearity. The radiation induced hardening within the damaged region, caused by a high density of radiation induced defects (i.e., point defects and dislocation loops), may have contributed to the increase in type II stresses when external load was applied. Another possible reason for the radiation induced hardening is the instability of nano-scale particles within the material. For example, the size of nano-scale particles can be significantly decreased after ion irradiation (the radiation damage level is less than $60 \mathrm{dpa}$ ) [49].

A major difficulty in this synchrotron experiment is setting the sample alignment in order to enable the high-energy $X$-ray to accurately penetrate the small radiation-damaged region. This alignment must be conducted at every stress-strain state during the intermittent tensile test; optimizing the sample orientation relative to the X-ray took 30-60 min. During the alignment, the tensile specimen was held by controlling load or displacement, and X-ray absorption measurements were performed periodically at different rotation-angles to search for the minimum absorption near the sample surface. This procedure is difficult to apply to the high-temperature tensile tests because the sample may creep during the alignment. To avoid a time-intensive alignment, a smaller specimen, for example, a wire sample with a diameter of $10 \mu \mathrm{m}$ or less, would be ideal for the high-energy X-ray measurement. Another option is a thin film specimen with a thickness of $30 \mu \mathrm{m}$ or less. In this case, the alignment time would be greatly reduced.

As shown in Figure 3, the radiation damage region is not uniform within the volume of measurement (i.e., to a $10 \mu \mathrm{m}$ depth from the sample surface). The lattice strains of the radiation-damaged region are the result of mixed and complicated responses to both injected interstitial and radiation damage that has huge variation over the region being analyzed. To interpret damage-level (or dpa level) dependent information amidst this complexity is extremely difficult. To better develop the capability to characterize radiation damage in materials by combining high-energy ion radiation and high-energy X-ray diffraction, a micron/submicron sized X-ray beam will be needed to probe into a specific region of interest in an irradiated sample. For example, an X-ray beam can be focused to $<2 \mu \mathrm{m}$ vertically at the beamline sector 1 at APS [50], and beamline sector 34 at APS can provide an X-ray beam with a beam size $<500 \mathrm{~nm}$ [51]. These focused X-ray beams without much loss in flux will significantly benefit the future studies of materials' ion-irradiation damage.

\section{Conclusions}

In this paper we have demonstrated the feasibility of combining high-energy ion radiation and high-energy synchrotron X-ray diffraction to study materials' radiation damage in a dynamic manner. The high-energy ion radiation produced a relatively large radiation-damaged region that demonstrates the possibility for study of the mechanical dynamic response of the region with applied stresses. Through in-situ X-ray measurement during the tensile test of ion-irradiated MA957, different loading behaviors of the irradiated and un-irradiated regions were observed within the specimen. With the same amount of applied stresses, lower lattice strains were found in the radiation-damaged region compared with those in the un-irradiated region. This difference might be associated with a higher level of Type II stresses as a result of the radiation hardening in the MA957 sample.

Acknowledgments: This work was supported by the U.S. Department of Energy under Contract No. DE-AC-02-06CH11357 between UChicago Argonne, LLC and the Department of Energy. The authors gratefully acknowledge the support of the International Institute for Carbon Neutral Energy Research (WPI-I2CNER), sponsored by the World Premier International Research Center Initiative (WPI), Ministry of Education, Culture, Sports, Science and Technology (MEXT), Japan. The authors would like to thank Carolyn Tomchik for editing the manuscript. This research used resources of the Advanced Photon Source, a U.S. Department of Energy (DOE) Office of Science User Facility operated for the DOE Office of Science by Argonne National Laboratory under Contract No. DE-AC02-06CH11357.

Author Contributions: Kun Mo and Michael Pellin conceived and designed the experiments; Di Yun, Yinbin Miao, Xiang Liu, Jonathan Almer, and Jun-Sang Park performed the APS experiment. Shaofei Zhu arranged and developed the plan for the ATLAS experiment. James F. Stubbins and Abdellatif M. Yacout contributed materials and analysis tools for the experiments.

Conflicts of Interest: The authors declare no conflict of interest. 


\section{References}

1. Ribis, J. Structural and chemical matrix evolution following neutron irradiation in a MA957 oxide dispersion strengthened material. J. Nucl. Mater. 2013, 434, 178-188. [CrossRef]

2. Fischer, J.J. Dispersion Strengthened Ferritic Alloy for Use in Liquid-Metal Fast Breeder Reactors (LMFBRS). U.S. Patent 4,075,010 A, 21 February 1978.

3. El-Genk, M.S.; Tournier, J.M. A review of refractory metal alloys and mechanically alloyed-oxide dispersion strengthened steels for space nuclear power systems. J. Nucl. Mater. 2005, 340, 93-112. [CrossRef]

4. Odette, G.R.; Alinger, M.J.; Wirth, B.D. Recent developments in irradiation-resistant steels. Annu. Rev. Mater. Res. 2008, 38, 471-503. [CrossRef]

5. Hadraba, H.; Kazimierzak, B.; Stratil, L.; Dlouhy, I. Microstructure and impact properties of ferritic ODS ODM401 (14\%Cr-ODS of MA957 type). J. Nucl. Mater. 2011, 417, 241-244. [CrossRef]

6. Wilshire, B.; Lieu, T.D. Deformation and damage processes during creep of incoloy MA957. Mater. Sci. Eng. A 2004, 386, 81-90. [CrossRef]

7. Alinger, M.J.; Odette, G.R.; Lucas, G.E. Tensile and fracture toughness properties of MA957: Implications to the development of nanocomposited ferritic alloys. J. Nucl. Mater. 2002, 307, 484-489. [CrossRef]

8. Yang, W.J.; Odette, G.R.; Yamamoto, T.; Miao, P.; Alinger, M.J.; Hribernik, M.; Lee, J.H. A critical stress-critical area statistical model of the $\mathrm{K}_{\mathrm{Jc}}(\mathrm{T})$ curve for MA957 in the cleavage transition. J. Nucl. Mater. 2007, 367, 616-620. [CrossRef]

9. Alinger, M.J.; Odette, G.R.; Hoelzer, D.T. On the role of alloy composition and processing parameters in nanocluster formation and dispersion strengthening in nanostuctured ferritic alloys. Acta Mater. 2009, 57, 392-406. [CrossRef]

10. Marquis, E.A. Core/shell structures of oxygen-rich nanofeatures in oxide-dispersion strengthened $\mathrm{Fe}-\mathrm{Cr}$ alloys. Appl. Phys. Lett. 2008, 93, 181904. [CrossRef]

11. Miller, M.K.; Hoelzer, D.T.; Kenik, E.A.; Russell, K.F. Stability of ferritic MA/ODS alloys at high temperatures. Intermetallics 2005, 13, 387-392. [CrossRef]

12. Wu, Y.; Haney, E.M.; Cunningham, N.J.; Odette, G.R. Transmission electron microscopy characterization of the nanofeatures in nanostructured ferritic alloy MA957. Acta Mater. 2012, 60, 3456-3468. [CrossRef]

13. Sakasegawa, H.; Legendre, F.; Boulanger, L.; Brocq, M.; Chaffron, L.; Cozzika, T.; Malaplate, J.; Henry, J.; de Carlan, Y. Stability of non-stoichiometric clusters in the MA957 ODS ferrtic alloy. J. Nucl. Mater. 2011, 417, 229-232. [CrossRef]

14. Sakasegawa, H.; Chaffron, L.; Legendre, F.; Boulanger, L.; Cozzika, T.; Brocq, M.; de Carlan, Y. Correlation between chemical composition and size of very small oxide particles in the MA957 ODS ferritic alloy. J. Nucl. Mater. 2009, 384, 115-118. [CrossRef]

15. Yamamoto, T.; Odette, G.R.; Miao, P.; Hoelzer, D.T.; Bentley, J.; Hashimoto, N.; Tanigawa, H.; Kurtz, R.J. The transport and fate of helium in nanostructured ferritic alloys at fusion relevant $\mathrm{He} / \mathrm{dpa}$ ratios and dpa rates. J. Nucl. Mater. 2007, 367, 399-410. [CrossRef]

16. Toloczko, M.B.; Gelles, D.S.; Garner, F.A.; Kurtz, R.J.; Abe, K. Irradiation creep and swelling from 400 to $600{ }^{\circ} \mathrm{C}$ of the oxide dispersion strengthened ferritic alloy MA957. J. Nucl. Mater. 2004, 329, 352-355. [CrossRef]

17. Toloczko, M.B.; Garner, F.A.; Maloy, S.A. Irradiation creep and density changes observed in MA957 pressurized tubes irradiated to doses of $40-110$ dpa at $400-750{ }^{\circ} \mathrm{C}$ in FFTF. J. Nucl. Mater. 2012, 428, 170-175. [CrossRef]

18. Ribis, J.; Lozano-Perez, S. Nano-cluster stability following neutron irradiation in MA957 oxide dispersion strengthened material. J. Nucl. Mater. 2014, 444, 314-322. [CrossRef]

19. Miller, M.K.; Hoelzer, D.T. Effect of neutron irradiation on nanoclusters in MA957 ferritic alloys. J. Nucl. Mater. 2011, 418, 307-310. [CrossRef]

20. Bailey, N.A.; Stergar, E.; Toloczko, M.; Hosemann, P. Atom probe tomography analysis of high dose MA957 at selected irradiation temperatures. J. Nucl. Mater. 2015, 459, 225-234. [CrossRef]

21. Was, G.S.; Jiao, Z.; Getto, E.; Sun, K.; Monterrosa, A.M.; Maloy, S.A.; Anderoglu, O.; Sencer, B.H.; Hackett, M. Emulation of reactor irradiation damage using ion beams. Scr. Mater. 2014, 88, 33-36. [CrossRef] 
22. Toloczko, M.B.; Garner, F.A.; Voyevodin, V.N.; Bryk, V.V.; Borodin, O.V.; Mel'nychenko, V.V.; Kalchenko, A.S. Ion-induced swelling of ODS ferritic alloy MA957 tubing to 500 dpa. J. Nucl. Mater. 2014, 453, 323-333. [CrossRef]

23. Was, G.S. Fundamentals of Radiation Materials Science; Springer: New York, NY, USA, 2007.

24. Lin, J.L.; Mo, K.; Yun, D.; Miao, Y.; Liu, X.; Zhao, H.; Hoelzer, D.T.; Park, J.S.; Almer, J.; Zhang, G.; et al. In situ synchrotron tensile investigations on 14 YWT, MA957, and 9-Cr ODS alloys. J. Nucl. Mater. 2015. in press. [CrossRef]

25. Biersack, J.P.; Haggmark, L.G. A Monte Carlo computer program for the transport of energetic ions in amorphous targets. Nucl. Instrum. Methods 1980, 174, 257-269. [CrossRef]

26. Ziegler, J.F.; Biersack, J.P. The Stopping and Range of Ions in Matter; Springer: New York, NY, USA, 1985; pp. 93-129.

27. Stoller, R.E.; Toloczko, M.B.; Was, G.S.; Certain, A.G.; Dwaraknath, S.; Garner, F.A. On the use of SRIM for computing radiation damage exposure. Nucl. Instrum. Methods Phys. Res. Sect. B 2013, 310, 75-80. [CrossRef]

28. Pan, X.; Wu, X.; Mo, K.; Chen, X.; Almer, J.; Ilavsky, J.; Haeffner, D.R.; Stubbins, J.F. Lattice strain and damage evolution of $9 \%-12 \% \mathrm{Cr}$ ferritic/martensitic steel during in situ tensile test by X-ray diffraction and small angle scattering. J. Nucl. Mater. 2010, 407, 10-15. [CrossRef]

29. Young, M.L.; Almer, J.D.; Daymond, M.R.; Haeffner, D.R.; Dunand, D.C. Load partitioning between ferrite and cementite during elasto-plastic deformation of an ultrahigh-carbon steel. Acta Mater. 2007, 55, 1999-2011. [CrossRef]

30. Hedström, P.; Lindgren, L.E.; Almer, J.; Lienert, U.; Bernier, J.; Terner, M.; Odén, M. Load partitioning and strain-induced martensite formation during tensile loading of a metastable austenitic stainless steel. Metall. Mater. Trans. A 2009, 40, 1039-1048. [CrossRef]

31. Cheng, S.; Wang, Y.D.; Choo, H.; Wang, X.L.; Almer, J.D.; Liaw, P.K.; Lee, Y.K. An assessment of the contributing factors to the superior properties of a nanostructured steel using in situ high-energy $\mathrm{X}$-ray diffraction. Acta Mater. 2010, 58, 2419-2429. [CrossRef]

32. Mo, K.; Zhou, Z.; Miao, Y.; Yun, D.; Tung, H.M.; Zhang, G.; Chen, W.; Almer, J.; Stubbins, J.F. Synchrotron study on load partitioning between ferrite/martensite and nanoparticles of a 9Cr ODS steel. J. Nucl. Mater. 2014, 455, 376-381. [CrossRef]

33. Mo, K.; Tung, H.M.; Li, M.; Almer, J.; Chen, X.; Chen, W.; Hansen, J.B.; Stubbins, J. Synchrotron radiation study on Alloy 617 and Alloy 230 for VHTR application. J. Press. Vess. Technol. Trans. ASME 2013, 135, 759-766. [CrossRef]

34. Daymond, M.R.; Bourke, M.A.M.; von Dreele, R.B.; Clausen, B.; Lorentzen, T. Use of rietveld refinement for elastic macrostrain determination and for evaluation of plastic strain history from diffraction spectra. J. Appl. Phys. 1997, 82, 1554-1562. [CrossRef]

35. Clausen, B.; Lorentzen, T.; Bourke, M.A.M.; Daymond, M.R. Lattice strain evolution during uniaxial tensile loading of stainless steel. Mater. Sci. Eng. A 1999, 259, 17-24. [CrossRef]

36. Clausen, B.; Bourke, M.A.M.; Brown, D.W.; Ustundag, E. Load sharing in tungsten fiber reinforced kanthal composites. Mater. Sci. Eng. A 2006, 421, 9-14. [CrossRef]

37. Daymond, M.R. The determination of a continuum mechanics equivalent elastic strain from the analysis of multiple diffraction peaks. J. Appl. Phys. 2004, 96, 4263-4272. [CrossRef]

38. Wang, L.Y.; Li, M.; Almer, J. Investigation of deformation and microstructural evolution in grade 91 ferritic-martensitic steel by in situ high-energy X-rays. Acta Mater. 2014, 62, 239-249. [CrossRef]

39. Wang, L.; Li, M.; Almer, J. In situ characterization of grade 92 steel during tensile deformation using concurrent high energy X-ray diffraction and small angle X-ray scattering. J. Nucl. Mater. 2013, 440, 81-90. [CrossRef]

40. Li, M.; Wang, L.Y.; Almer, J.D. Dislocation evolution during tensile deformation in ferritic-martensitic steels revealed by high-energy X-rays. Acta Mater. 2014, 76, 381-393. [CrossRef]

41. He, B.B. Introduction to two-dimensional X-ray diffraction. Powder Diffr. 2003, 18, 71-85. [CrossRef]

42. Miao, Y.; Mo, K.; Zhou, Z.; Liu, X.; Lan, K.C.; Zhang, G.; Miller, M.K.; Powers, K.A.; Mei, Z.G.; Park, J.S.; et al. On the microstructure and strengthening mechanism in oxide dispersion-strengthened 316 steel: A coordinated electron microscopy, atom probe tomography and in situ synchrotron tensile investigation. Mater. Sci. Eng. A 2015, 639, 585-596. [CrossRef] 
43. Miao, Y.; Mo, K.; Zhou, Z.; Liu, X.; Lan, K.C.; Zhang, G.; Miller, M.K.; Powers, K.A.; Almer, J.; Stubbins, J.F. In situ synchrotron tensile investigations on the phase responses within an oxide dispersion-strengthened (ODS) 304 steel. Mater. Sci. Eng. A 2015, 625, 146-152. [CrossRef]

44. Zhang, G.; Mo, K.; Miao, Y.; Liu, X.; Almer, J.; Zhou, Z.; Stubbins, J.F. Load partitioning between ferrite/martensite and dispersed nanoparticles of a $9 \mathrm{Cr}$ ferritic/martensitic (F/M) ODS steel at high temperatures. Mater. Sci. Eng. A 2015, 637, 75-81. [CrossRef]

45. Zhang, G.; Zhou, Z.; Mo, K.; Miao, Y.; Liu, X.; Almer, J.; Stubbins, J.F. The evolution of internal stress and dislocation during tensile deformation in a $9 \mathrm{Cr}$ ferritic/martensitic (F/M) ODS steel investigated by high-energy X-rays. J. Nucl. Mater. 2015, 467, 50-57. [CrossRef]

46. Stoica, G.M.; Stoica, A.D.; Miller, M.K.; Ma, D. Temperature-dependent elastic anisotropy and mesoscale deformation in a nanostructured ferritic alloy. Nat. Commun. 2014, 5, 5178. [CrossRef] [PubMed]

47. Hutchings, M.T.; Withers, P.J.; Holden, T.M.; Lorentzen, T. Introduction to the Characterization of Residual Stress by Neutron Diffraction; Taylor \& Francis Group LLC: Abingdon, UK, 2005.

48. Mo, K. Microstructural Evolution and Mechanical Behavior in Nickel Based Alloys for very High Temperature Reactor. Ph.D. Thesis, University of Illinois at Urbana-Champaign, Urbana, IL, USA, 2011.

49. Chen, T.; Aydogan, E.; Gigax, J.G.; Chen, D.; Wang, J.; Wang, X.; Ukai, S.; Garner, F.A.; Shao, L. Microstructural changes and void swelling of a 12Cr ODS ferritic-martensitic alloy after high-dpa self-ion irradiation. J. Nucl. Mater. 2015, 467, 42-49. [CrossRef]

50. Shastri, S.D.; Almer, J.; Ribbing, C.; Cederstrom, B. High-energy X-ray optics with silicon saw-tooth refractive lenses. J. Synchrotron Radiat. 2007, 14, 204-211. [CrossRef] [PubMed]

51. Hofmann, F.; Nguyen-Manh, D.; Gilbert, M.R.; Beck, C.E.; Eliason, J.K.; Maznev, A.A.; Liu, W.; Armstrong, D.E.J.; Nelson, K.A.; Dudarev, S.L. Lattice swelling and modulus change in a helium-implanted tungsten alloy: X-ray micro-diffraction, surface acoustic wave measurements, and multiscale modelling. Acta Mater. 2015, 89, 352-363. [CrossRef]

(C) 2016 by the UChicago Argonne LLC, with certain rights reserved by the U.S. Government; licensee MDPI, Basel, Switzerland. This article is an open access article distributed under the terms and conditions of the Creative Commons by Attribution (CC-BY) license (http://creativecommons.org/licenses/by/4.0/). 